\title{
Thirsty rats do prefer sucrose solutions
}

ROBERT C. BECK and RICHARD NASH, ' Wake Forest University, WinstonSalem, N. C. 27109

In three experiments it was demonstrated that water-deprived rats preferred sucrose solutions to water or lower concentration sucrose within the first 5 min of a test period. The preferences were as great as those shown by fooddeprived rats. An hypothesis is offered to explain the discrepancy between these results and the indiscriminate behavior of rats towand sucrose solutions in barpressing situations.

Within limits, the higher the concentration of sucrose offered the satiated or food-deprived rat the greater its responsiveness toward the solution with reference to consummatory, instrumental, or choice behavior (e.g., Beck \& Ellis, 1966; Campbell, 1958; Collier \& Myers, 1961; Young, 1966). Many experiments have shown, however, that the water-deprived rat does not show this effect. It responds indiscriminately for water or different sucrose solutions in bar pressing situations (e.g., Beck, 1963; Collier, 1964; Oakley, 1965) until the sucrose reaches some high level of concentration (hypertonic) at which point it begins to prefer water over sucrose (Beck \& Ellis, 1966). Indication that thirsty rats do prefer sucrose, however, comes from a study by Beck, Self, \& Carter (1965) who found a higher sucrose preference threshold for waterdeprived (1.28\%) than for nondeprived (.43\%) rats in 4-min tests, but nevertheless a preference. In the present experiments short-term sucrose preferences of rats under food and water deprivation were studied.

\section{EXPERIMENT 1}

Subjects and Apparatus

The Ss were six female albino rats, about 90 days old, housed in individual hanging cages. The nondeprived commodity was continuously available in the home cages but Ss ate or drank the deprived commodity (lab chow or water) in different cages. Only the test solutions were in the test apparatus.

The apparatus, described by Beck et al (1965), consisted of two $10 \times 5 \times 5^{1 / 2-i n}$. wooden boxes, into the Plexiglas ends of which a pair of stainless steel drinking spouts leading from gas measuring tubes could be inserted. The 2-5/8-in. holes in the Plexiglas were $23 / 4 \mathrm{in}$. from the floor and $13 / 4 \mathrm{in}$. apart, center to center. Tongue licks were detected by drinkometer circuits and were recorded at $1-\mathrm{min}$ intervals on Sodeco printout counters in an adjacent room. An electric color wheel provided masking noise.

\section{Design and Procedure}

Three pairs of sucrose solutions were used for tests: 0 (distilled water) vs $6 \%, 6$ vs $12 \%$, and 12 vs $18 \%$. Percentages were grams table sugar per $100 \mathrm{ml}$ of solution. Solutions were mixed several days in advance of use, were refrigerated in stoppered flasks, and were warmed to room temperature prior to use. Drinking tubes, spouts, and test boxes were cleaned daily.

The six Ss were divided into two groups of three. One group was tested with all pairs of solutions in a Latin square order during 23-h food deprivation, and the other during 23-h water deprivation. Each pair of solutions was tested on 2 consecutive days, reversing solution positions. One $\mathrm{S}$ from each group was tested at any particular time. When the first Latin square was completed Ss were adapted to the alternate deprivation condition and retested with the same solutions in a different Latin square.

All Ss were given initial apparatus and discrimination training during 23-h food deprivation, using 0 vs $18 \%$ in alternating positions daily. As training progressed the spouts were gradually adjusted out from the holes until Ss could reach them only with their tongues. When Ss were consistently showing a strong sucrose preference in the daily $20-\mathrm{min}$ period, half of them were adapted to the water-deprivation schedule for 5 days before starting testing. On the first 3 days all $S s$ were placed in the apparatus without drinking tubes and on the last 2 days were given 0 vs $18 \%$ in the two tubes for 20 -min periods. The same 5 -day adaptation regime was followed when Ss were switched to the alternate deprivation conditions for the second set of tests.

On each day of training and testing two drops of the appropriate solutions were placed on the lower edges of the holes through which the tubes containing the solutions would be reached. After both Ss had taken these (they always did) the two tubes were simultaneously put into position. After 20 min of drinking Ss were removed to eating or drinking cages for $1 \mathrm{~h}$ before being returned to the home cages. Results

Figure 1 summarizes the results of all the tests in the experiment, showing the mean per cent preference for the more concentrated solution in each pair. Since a number of $\mathrm{Ss}$ did not drink in the first minute of a test the mean preferences in the second minute of each test are shown, as well as the means for Minutes 2-5 inclusive and the entire 20-min tests.

Reading across the top of the graph for the $0-6 \%$ pair, the most obvious point is that the preferences are very high and virtually identical for the two deprivation conditions, all means being above $85 \%$ for the three time periods. Furthermore the preference was shown by all Ss under both deprivation conditions within the second minute of drinking. In fact, only five of the 36 individual preference scores represented in the $0-6 \%$ comparisons were less than $90 \%$. Three of these came in the second minute, two in Minutes 2-5, and two were under food deprivation in the second minute. In brief, all Ss showed a preference for $6 \%$ sucrose over water as soon as they had made enough licks to provide scorable data and before any significant degree of water satiation. The preferences with the two higher concentration pairs were progressively smaller, as would be expected from Weber's law and Campbell's (1958) data, but there were no significant differences between deprivation conditions. The conclusions to be drawn from these data, then, are (1) water-deprived Ss under the conditions of this experiment show as great a sucrose preference as do food-deprived Ss, and (2) this preference, in the case of 0 vs $6 \%$, appears almost immediately at the beginning of a test session. This indicates that the preference is mediated by a taste difference which is dominant under water deprivation without the necessity of prior water satiation.

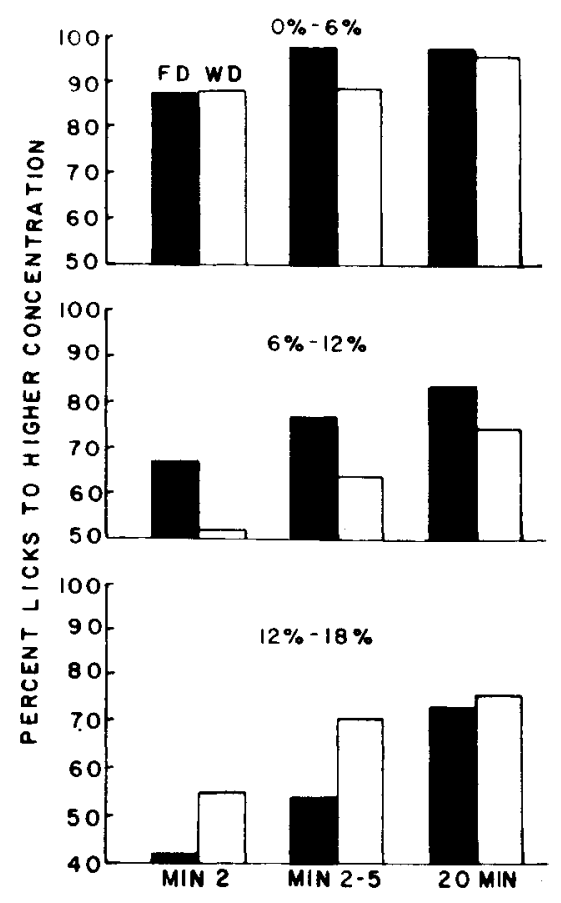

Fig. 1. Mean percentage of licks to the more concentrated member of each pair of solutions. Percentages determined by the formula: number of licks to the higher concentration divided by the total number of licks. 


\section{EXPERIMENT 2}

Since all $S$ s in Experiment 1 had been given initial training with water vs sucrose while food deprived it might be suggested that during the course of training the Ss developed a preference for sucrose based on its association with caloric need reduction. This might then have carried over into the water deprivation tests. As a check on this possibility four new Ss were trained and tested over a period of 8 days only under 23.5 -h water deprivation, using only 0 vs $6 \%$ sucrose. The testing began at the end of the first day on the deprivation schedule, with tube positions alternated daily. On the first 2 days performance in the second minute of testing was erratic, as would be expected. The per cent sucrose preferences for the four Ss were $6 \%, 31 \%$, $52 \%$, and $94 \%$. The $20-\mathrm{min}$ preferences, however, were $66 \%, 64 \%, 82 \%$, and $92 \%$. On Test Days 3-8, however, the mean sucrose preferences for the four Ss in the second minute were $86 \%, 69 \%, 64 \%$, and $80 \%$; in Minutes $2-5$ they were $75 \%, 56 \%$, $82 \%, 94 \%$, and in the total $20 \mathrm{~min}$ they were $88 \%, 94 \%, 61 \%$, and $95 \%$. In other words, in the first 2 days of testing all Ss were showing a sucrose preference in the total $20 \mathrm{~min}$ but on Days 3.8, within the second minute. Since this preference was being shown without previous association of sucrose with hunger reduction it would appear that it is a taste preference characteristic of the water-deprived rat.

\section{EXPERIMENT 3}

In this experiment, within-session wate satiation was reduced by the use of saline stomach loads to make the Ss more thirsty. The Ss were four male albino rats which had previously been exposed to $6 \%$ sucrose while thirsty, but not in a choice situation. They were trained for 6 days with 0 vs $6 \%$ sucrose during $23.5 \mathrm{~h}$ water deprivation, having already been adapted to the water deprivation schedule. Solution positions were alternated daily. After the sixth day of training each S's preferred drinking position (right or left) was determined and on the first and third salt-load test days, water was on the preferred side. On the 7 th, 9 th, and 11 th days of the experiment each $S$ was weighed, lightly etherized and stomacl loaded with $2 \%$ body weight of $4 \%$ saline, which considerably enhances drinking (O'Kelly \& Beck, 1960). Folluwing a $60-\mathrm{min}$ delay without access to food or water $\mathrm{Ss}$ were given the standard $20-\mathrm{min}$ test. The day after each load was a recovery day with Ss run as in training.
Sucrose preferences in the early part of each session in this experiment were not as great as in the first two experiments. On load days, however, preferences were somewhat higher than on the training days just prior to the load days. The mean preferences for the four Ss for Training Days 6 plus 10 and Load Days 7 plus 11 (all days when water was on the preferred side) were: second minute, $26 \%$ and $41 \%$; Minutes $2.5,37 \%$ and $61 \%$; and $20-\mathrm{min}$ total, $71 \%$ and $85 \%$. The median $20 \mathrm{~min}$ preferences for the four Ss over the three load days were $98 \%, 75 \% 97 \%$, and $91 \%$. Although it is not entirely clear why the preferences in the early part of the sessions of this experiment were lower than in the previous experiments it is clear that making Ss more thirsty by salt loading did not reduce their preferences.

\section{DISCUSSION}

The general empirical conclusions to be drawn from these studies are that (1) water-deprived rats under these testing conditions do prefer sucrose over water or lower concentration sucrose, and (2) experience with sucrose only when water deprived is sufficient to show the sucrose preference over water. Why were such clearcut preferences shown in these experiments when they have not been obtained in others? We suggest the following threefold explanation. First, the sucrose acceptance function for the waterdeprived rat is shallower than for the nondeprived or food-deprived rat (for which it is steepest). This is inferred from the facts that in some situations, e.g., bar pressing, a preference for sucrose is not shown by the water-deprived rat but the preference apparently does exist according to the present data. Second, with both tubes continuously available in the present experiments, contact with the sucrose provided more or less continuous stimulation of approach responses, kecping the $S_{s}$ oriented to the higher concentration tube and away from the lower. In situations involving removal of the sucrose, as in bar pressing on a schedule of rcintorcement. any differential approach stimulation decays during the time the sucrose is not present and $\mathrm{S}$ therefore responds about equally for all solutions because they are of such nearly equal acceptance. Thirdly, a methodological point, the Ss here. especially in Experiment 1, were well-trained at the task and had appropriate cues to guide them in their initial choice of tubes during a session. The drops of solution in the holes where the tubes were to be presented "told" Ss where the more preferred concentration was going to appear. Thus, Ss did not lock immediately onto the water tube in random fashion and then stay with it so long that a demonstrable sucrose preference early in the session was destroyed. This could easily happen since in an absolute sense water is highly acceptable to the thirsty rat.

In summary, then, we suggest the main principle involved is that water deprivation produces a flatter sucrose acceptance (or "approach arousal") function than does food deprivation and therefore more optimal test conditions are required to demonstrate a sucrose preference with water-deprived Ss than with food-deprived.

\section{REFERENCES}

$B E C K, R . C$. Effects of variations in water need and incentive concentration on bar pressing. Psychological Reports, 1963, 13, 31-37.

BECK, R. C., \& ELLIS, V. T. Sucrose reinforcement thresholds for hungry, thirsty, and non-deprived rats. Psychonomic Science, 1966, 4, 199-200.

BECK, R. C., SELF, J. L., \& CARTER, D. J. Sucrose preference thresholds for satiated and water-deprived rats. Psychological Reports, 1964, 16, 901-905.

CAMPBELL, B. A. Absolute and relative sucrose preference thresholds for hungry and satiated rats. Joumal of Comparative \& Physiological Psychology, 1958, 57, 795-800.

COLLIER, G. Thirst as a determinant of reinforcement. In M. J. Wayner (Ed.), Thirst. London: Pergamon, 1964.

COLLIER, G., \& MYERS, L. The loci of reinforcement. Journal of Experimental Psychology, 1961, 61, 57-66.

OAKLEY, B. Impaired operant behavior following lesions of the thalamic taste nucleus. Journal of Comparative \& Physiological Psychology, 1964, 59. 202-210.

O'KI:LLY, L. I., \& BIC K, R. C. Water regulation in the rat: III. The artificial control of thirst with stomach loads of water and sodium chloride. Psychological Monographs: (jeneral \& Applied, 1960.74. (13, Whole No. 500).

YOUNG, P. T. Hedonic organization and the regulation of behavior. Psychological Review, $1966,73,59-86$.

\section{NOTE}

1. Present address: Department of Psychology, Tulane (Iniversity. Fxperiment 1 was conducted by the junior author under the direction of the senior author in partial fultillment of undergraduate honors requirements at Wake lorest. The support of this research by Grant No. HD-00937 from the National Institute of Child Health and Human Developnent is gratefully acknowledged. This research was conducted in accordance with the Principles for the Care and Use of Animals adopted by the APA. June 26.1968. 